\title{
O dharma verde-amarelo mal-sucedido - um esboço da acanhada situação do Budismo
}

\author{
FRANK USARSKI
}

\section{O suposto sucesso do Budismo brasileiro - boatos e dúvidas}

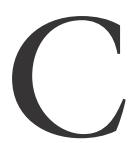

OMO SE SE RECITASSE um "mantra” cujo efeito se intensifica a cada repetição, a mídia brasileira tem divulgado com uma regularidade imperturbável informações sobre o "avanço do Budismo" ". Jornalistas e repórteres inspirados em fontes "obscuras" fazem com que seus leitores acreditem que o Budismo, devido à saída dos seus templos tradicionais ${ }^{2}$, vem crescendo de maneira cada vez mais acelerada e já conta com até um milhão de fiéis no país ${ }^{3}$. Para aumentar a credibilidade de tais estereótipos, são freqüentemente citadas celebridades como Claudia Raia ${ }^{4}$, Betty Faria ${ }^{5}$, Odete Lara, Lucélia Santos, Ney Matogrosso ${ }^{6}$, Heródoto Barbeiro, Soninha Francine ${ }^{7}$ e outros ${ }^{8}$, cujos depoimentos em nome do dharma, ou seja, a favor da doutrina budista e de suas práticas, são tratados como se fossem representativos de um processo maciço e irreversível da "orientalização" do campo religioso brasileiro.

A tenacidade com a qual a imagem positiva do Budismo mantém-se na consciência pública surpreende, uma vez que nem é preciso um conhecimento especializado para entender que a idealização pública da situação do Budismo no país não é nada mais do que uma das múltiplas manifestações da tendência internacional de que “o espaço reservado nos jornais para um grupo religioso é quase diretamente inverso ao seu peso estatístico e à sua convencionalidade" ${ }^{10}$. Para não cair em uma armadilha retórica sensacionalista, basta ser um cidadão atento e crítico para comparar as notícias auspiciosas sobre o Budismo com informações sobre outros fenômenos religiosos menos “exóticos”. Entre janeiro e agosto de 2001, por exemplo, o leitor encontrou em jornais e revistas diversos artigos sobre as chamadas "caminhadas no parque", ou seja, sobre um grupo de praticantes da meditação que meditavam caminhando, atividade essa organizada pela Monja Coen, "uma das principais representantes da escola zen-budista no País"11. Segundo a mídia, essa prática dominical teve início com doze pessoas no Parque da Aclimação ${ }^{12}$ e chegou numericamente ao seu auge em agosto de 2001 . Nessa época, um pouco mais do que cem pessoas participaram do movimento ${ }^{13}$. Podese assumir que as freqüentes reportagens sobre a Monja Coen e sua "fila indiana silenciosa" aumentaram a fama da já conhecida organizadora. Em termos numé- 
ricos, porém, as notícias revelam que o Budismo representa, na verdade, um segmento do campo religioso brasileiro relativamente insignificante. Vale a pena lembrar que a Monja se esforçou por seis meses para aumentar seu movimento de doze para cerca de cem membros, enquanto um evento anual como a "Marcha para Jesus", sob a tutela da Igreja Renascer em Cristo, atrai regularmente milhares de evangélicos ${ }^{14}$. Diante de tal dado contrastante pergunta-se a que fatos os jornalistas e repórteres se referem quando divulgam a informação de que o Budismo "conquista, mais e mais, fiéis de outras religiões"? 15

Com argumentos semelhantes pode-se problematizar também um outro "indício" do suposto "enorme sucesso" do Budismo no Brasil. Em outubro de 2003, foi inaugurado o novo Templo Zu Lai, sede da corrente budista taiwanes Fo Kuang Shan. Trata-se de uma das maiores construções budistas da América Latina e que, no futuro, alojará a primeira faculdade budista do Brasil. Cerca de duas mil pessoas, incluindo uma comitiva de quinhentos taiwaneses que acompanhavam o convidado especial ${ }^{16}$, o fundador do Fo Kuang Shan, mestre Hsing Yun, participaram da festa e da cerimônia de sua consagração ${ }^{17}$. Em vários artigos e programas de televisão, a futura função do templo e o fato de que foram investidos doze milhões de reais na compra do terreno e nos dez mil metros quadrados de área construída em um autêntico estilo chinês ${ }^{18}$ foram interpretados como sinais de um enraizamento definitivo do Budismo na cultura brasileira.

Não se nega o forte simbolismo dessa nova instituição impressionante, mas há bons motivos para se duvidar que, com a futura planejada faculdade budista e com a construção do novo templo, o Budismo realmente tenha atingido um novo patamar da sua existência no Brasil. Enquanto os adeptos do movimento taiwanês comemoram a possível inserção do Budismo no campo acadêmico, um olhar mais distante relativiza essa euforia pelo fato de que apenas na primeira metade de 2004 o Ministério da Educação

já autorizou [...] o funcionamento de 1.760 novos cursos de ensino superior no país. São, em média, 3,4 cursos abertos por dia. Esse número ainda pode aumentar porque não inclui dados referentes a universidades e centros universitários, que têm autonomia e não precisam de autorização do MEC para abrir cursos, exceto os localizados fora da sede ${ }^{19}$.

Diante do caráter inflacionário de cursos acadêmicos atualmente oferecidos no meio acadêmico brasileiro, ainda não se pode prever se a demanda por uma formação budista corresponde às expectativas otimistas dos seus responsáveis.

Quanto à opulência do novo templo e o número de participantes em sua inauguração, vale a pena uma comparação com alguns dados referentes à Igreja Universal de Reino de Deus. Quando, por exemplo, em Io de fevereiro de 1998, o Bispo Macedo consagrou, no Bairro de Santo Amaro em São Paulo, um novo mega-templo com um interior espaçoso, a cerimônia de abertura contou com a presença de mais do que dez mil pessoas sentadas e uma "multidão" não quantificada que esperava do lado de fora ${ }^{20}$. Atualmente, a situação da Igreja Universal é 
ainda mais auspiciosa, uma vez que apenas uma sede estadual como a de Minas Gerais, inaugurada em abril de 2004, possui 28 mil metros quadrados ${ }^{21}$. Embora essas informações estejam acessíveis a qualquer leitor de um jornal nacional, elas não impedem que os próprios representantes da mídia brasileira continuem a publicar reportagens e artigos sobre o suposto crescimento do Budismo no país.

\section{Problematização}

Pode-se assumir que a imagem do sucesso do Budismo, freqüentemente divulgada pela mídia nacional, é, em parte, causada pela falta de reflexão sobre a pergunta: "quem é realmente um budista?". Alguns pesquisadores da religião de outros países ocidentais já se ocuparam desse assunto ${ }^{22}$, chamando a atenção para a relação entre a "demanda" e a oferta "religiosa", ou seja, para o fato de que o grau de comprometimento com o Budismo depende não apenas da disponibilidade do indivíduo para aderir preferencialmente ou, até mesmo, exclusivamente, a uma determinada comunidade budista, mas também do grau de institucionalização que o Budismo se apresenta para o público ocidental. No que diz respeito ao primeiro aspecto, tem-se que levar em conta o fato de que o Brasil é visto como um país cujos habitantes mostram em grande escala uma "múltipla afiliação religiosa" devido a uma mentalidade coletiva na qual o "ecletismo é profundamente enraizado" 23 .

Quanto à “oferta”, é relevante observar que o Budismo ocidental contemporâneo apresenta-se a seu público com múltiplas facetas, ou seja, não apenas em formas obviamente institucionalizadas, mas também de maneira sociologicamente menos concreta ou, até mesmo, difusa. Conforme os sociólogos norte-americanos Rodney Stark e William S. Bainbridge, o mesmo fenômeno encontra-se na área da chamada“"nova religiosidade”, cujas diversas expressões sociais podem ser categorizadas de acordo com três níveis de institucionalização ${ }^{24}$, as quais eles classificam como: cult movement, client cult e audience.

As manifestações mais "densas" representam o tipo de um cult movement que é administrado por uma hierarquia provida de um "poder de definição", comprometida com uma determinada tradição de doutrinas e práticas "canonizadas", ou seja, com um "capital religioso" a ser mantido e transmitido o mais autenticamente possível. Esse tipo de grupo é constituído por membros que compartilham de uma cosmovisão sistematizada específica, seguem padrões de inter-relações internas e regras éticas em tensão simbólica e comportamental com o ambiente "externo" da própria comunidade. Traços semelhantes, especificamente aspectos como uma estratificação interna, um determinado grau de coesão dos membros e a "distância" da "oferta" religiosa com o "senso comum" da sociedade geral encontram-se também no campo do Budismo. Basta pensar em alguns templos budistas japoneses fundados por imigrantes, ministrados por especialistas religiosos formados no Japão, freqüentados por famílias de descendentes atraídos por cultos tradicionais realizados na sua língua de origem. Há 
diversos outros exemplos fora do ambiente étnico como o Soka Gakkai, que, embora sua cúpula seja predominante de integrantes da comunidade nikkei, hoje cerca de $90 \%$ de seus membros não tem ascendência japonesa e é conhecida por seu fervor proselitista baseado em uma estrutura organizadora elaborada e efi$\mathrm{caz}^{25}$; ou a "New Kadampa Tradition” fundada por Geshe Kelsang Gyatso, cuja versão do Budismo é divulgada no Ocidente através de um movimento estritamente padronizado e estratificado em graus cada vez mais elevados no sentido de conhecimento e responsabilidade interna, cujos níveis mais avançados são representados por monges e monjas facilmente identificáveis por suas roupas tradicionais tibetanas.

De acordo com o sistema de categorias proposto por Stark e Bainbridge, o segundo nível de institucionalização na área de "nova religiosidade" é representado por client cults, ou seja, por uma dinâmica que exige menos compromisso do que um cult movement. Como a palavra inglesa indica, pode-se pensar um client cult em termos de uma estrutura dialógica gerada pela inter-relação entre uma "clientela" carente de um determinado aspecto supostamente relevante para o desenvolvimento espiritual e um "especialista" considerado mais avançado naquela área. Portanto, diferentemente de um cult movement que, às vezes, "absorve" grande parte do dia-a-dia de membros "definitivos" sob a "supervisão" de uma hierarquia religiosa, um client cult é apenas uma cristalização temporal e pontual a ser abandonada pelo cliente no momento em que o "terapeuta" cumpriu seu "serviço" específico. Entre os diversos exemplos que apontam para o fato de que o campo do Budismo ocidental é estruturado de maneira analógica e implica também formas institucionais do tipo de um client cult, encontra-se o grupo de meditação oferecido pela superiora do Templo Zu Lai, Monja Sinceridade, para funcionários e pacientes do Hospital do Servidor Público Munici$\mathrm{pal}^{26}$. Pode-se assumir que, para a grande maioria dos participantes, essas atividades passageiras não tenham levado a uma conversão propriamente dita ao Budismo chinês, mas tenham sido recebidas como mais uma possibilidade de enriquecer o depósito pessoal de ensinamentos e práticas em função do crescimento pessoal. Portanto, embora uma técnica budista tenha desempenhado um papel construtivo na vida dos integrantes daquele grupo, o impacto não foi suficientemente profundo para transformar os autoconceitos dos participantes em identidades budistas no sentido estrito da palavra. O mesmo vale para uma clientela transitória que se vincula apenas em determinadas ocasiões à estrutura física de uma instituição budista para desfrutar de algumas ofertas específicas abertas ao grande público. Um exemplo é o Centro de Dharma em São Paulo que, embora o núcleo dessa comunidade da linha do Budismo Tibetano seja composto por aderentes propriamente ditos, exerce diversas atividades no nível de um client cult, entre outras, “oficinas” e cursos de curta duração cujos conteúdos nem sempre são imediatamente associáveis ao Budismo tibetano ou, até mesmo, são oriundos de outras tradições orientais ${ }^{27}$. Não se nega a possibilidade de que eventos 
desse tipo possam facilitar a adesão mais firme à instituição organizadora declaradamente budista ou, até mesmo, promover a conversão ao Budismo tibetano. Todavia, é plausível a hipótese de que a atuação em dois níveis seja, em primeiro lugar, uma resposta institucional a uma demanda diferenciada, inclusive a de "simpatizantes" caracterizados por uma certa "afinidade" com o Budismo, mas ainda não suficientemente acentuada para se deslocar da margem do campo budista e se aproximar mais do centro e de seus representantes comprometidos.

A dificuldade de identificar alguém como budista torna-se ainda mais evidente no terceiro nível institucional que, segundo Stark e Bainbridge, é caracterizado como uma rede abstrata cujos integrantes estão apenas indiretamente relacionados. Trata-se da chamada audience, ânstituída por indivíduos que geralmente nem se conhecem, mas que compartilham os mesmos valores, e motivados por interesses comuns, freqüentam eventos semelhantes, são "fregueses" do mesmo "mercado", e assim por diante. Possíveis lugares de encontros esporádicos e impessoais seriam, por exemplo, uma banca de jornal no dia do lançamento do novo número de uma revista como Planeta, ou um stand em uma "feira mística" onde se pode comprar utensílios esotéricos para uso doméstico. Repensando esses traços com relação à estrutura das ofertas na área do Budismo, deve ser lembrado que no decorrer da história da admissão do Budismo no Ocidente, várias das suas doutrinas e práticas, originalmente desenvolvidas e transmitidas dentro de determinadas linhas budistas, "emanciparam-se" do seu contexto original e começaram a circular livremente, dando a impressão que se tratava de propriedade coletiva espiritual da "humanidade" publicamente disponível. Do ponto de vista das “ofertas”, pode-se dizer que a desvinculação da herança religiosa da sua autêntica base institucional imediatamente visível provocou o uso inflacionário de conceitos, símbolos e "produtos" budistas em inúmeras fontes, discursos diversos e contextos múltiplos. Visto sob o ângulo da "demanda", percebem-se reações diferentes a essa difusão de "bens religiosos" que, no passado, eram sistematicamente enraizados no ambiente da sua "produção" original. No seu extremo, o Budismo transforma-se em uma "religião invisível”, adotada por um público que possui as mesmas características atribuídas a uma audience. Conforme Gabriela Bastos Soares:

O budismo é visto como componente do cosmos sagrado da atualidade. Os principais aspectos que contribuem para essa afirmação são: o exercício a nível individual, privado, reconhecido como uma psicologia budista; o pragmatismo desse tipo de religião, fundamentada em regras úteis para o mundo; e a relação com outras pessoas e com o universo, que enaltece uma cosmovisão holística ${ }^{28}$.

Os enunciados expressam que o budismo possibilita ao homem experimentar e construir por si o conjunto de suas motivações religiosas. Como o cosmos sagrado atual permite a recorrência a temas heterogêneos ao religioso, cada um pode compor seu universo de sentido de forma particular - abertura para a variedade de fontes que o budismo valoriza ${ }^{29}$. 


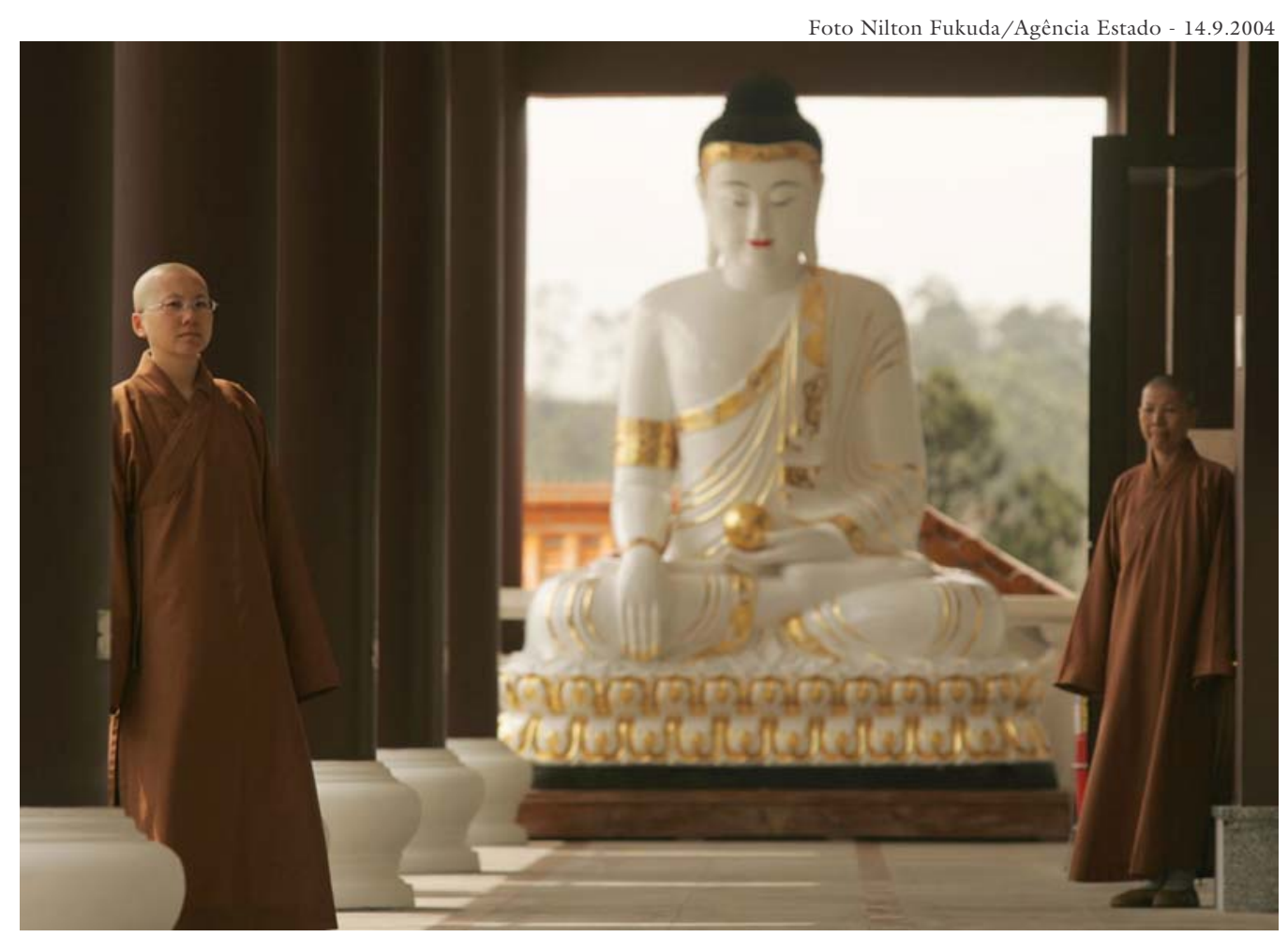

A mestra Zu Lai (à esq.) no interior do templo budista inaugurado em outubro de 2003.

\section{A situação do Budismo brasileiro a partir dos seus aderentes explícitos e suas formas inequivocamente institucionalizadas}

Em oposição a especulações públicas inadequadas e conceitualmente sem fundamento a respeito da situação do Budismo no Brasil, os dois últimos censos nacionais de 1991 e de 2000 chegaram a números muito mais confiáveis. Em vez de confirmar os prognósticos de um crescimento constante do Budismo no país, os resultados do IBGE revelaram um declínio quantitativo de budistas no período entre os dois censos.

Embora a metodologia usada pelo IBGE não seja isenta de problemas epistemológicos, ela é um avanço do ponto de vista empírico por considerar somente como seguidores do Budismo aqueles brasileiros que se manifestaram explicitamente como budistas de acordo com uma identidade religiosa correspondente. Por outro lado, foram automaticamente excluídas das estatísticas aquelas pessoas cuja religiosidade substancialmente mais ampla apropria-se de maneira seletiva e às vezes de maneira passageira de alguns elementos doutrinários ou práticas budistas, sem que isso resulte em um auto-reconhecimento do indivíduo como seguidor do Budismo.

A partir da distinção categorial entre uma "religiosidade tradicional" e uma "religiosidade internalizada" 30 e conforme a coexistência de dois tipos de Budismos no Ocidente, um "Budismo de Imigração" e um "Budismo de Conversão" 31 , a convicção subjetiva "eu sou budista” simbolizada por uma simples cruz 
na rubrica "religião" no questionário do IBGE oferece a possibilidade de duas leituras. Primeiro, uma auto-identificação como budista pode significar que o respondente é budista por nascimento e considera a religião transmitida por gerações dentro da sua família digna de se preservar, independente da profundidade do impacto dessa referência sobre sua própria fé e sua prática particular. A segunda subcategoria implícita nos números de budistas apontados pelo IBGE é composta por brasileiros sem ascendência asiática que, em um determinado momento de sua vida aderiram ao Budismo fazendo uma escolha consciente, suficientemente refletida e exclusivista para se autodefinir como seguidor dessa religião e não de uma outra.

Segundo os resultados do censo de 1991, havia 236.408 budistas naquela época no Brasil. Para avaliar de forma realista esse número, vale a pena comparálo com os dados referentes a duas minorias cristãs quase ignoradas pela discussão pública sobre tendências atuais e futuras no campo religioso do país: na mesma pesquisa do IBGE 752.576 brasileiros declararam-se testemunhas de Jeová e 706.409 pessoas declararam-se adventistas. Em outras palavras, no início dos anos 1990, cada um dos dois grupos publicamente considerados "marginais" teve um peso numérico três vezes maior do que o conjunto dos indivíduos contados como budistas. A discrepância entre a imagem do budismo brasileiro crescente e as estatísticas oficiais torna-se ainda mais gritante quando se confronta os dados de 1991 com os de 2000. No último censo nacional, apenas 214.873 pessoas identificaram-se como budistas. Portanto, em comparação com os números de 1991, apesar do crescimento da população brasileira de cerca de 15\% e diferentemente do aumento de número de adventistas (1.209.842 em 2000 devido a um crescimento de 503.433 seguidores) e de testemunhas de Jeová ( 1.104 .886 em 2000 devido a um crescimento de 352.310 pessoas) o Budismo sofreu um declínio absoluto de 21.532 adeptos entre 1991 e 2000. Isso significa que a relação entre os budistas brasileiros e os adventistas mudou de aproximadamente 1:3 em 1991 para 1:5 em 2000. O mesmo vale com respeito às testemunhas de Jeová.

Um outro fator importante para uma avaliação mais realista do status do Budismo consiste na exagerada desproporção entre budistas nas regiões urbanas e nas áreas rurais. Se o Budismo estivesse espalhado em território nacional de acordo com à situação domicílio da população residente haveria, para cada budista que vive no campo, um valor estatístico de 4,3 budistas em cada uma das cidades brasileiras. Na verdade, a relação é de aproximadamente 1:18,3, portanto, mostra-se que o budismo brasileiro é um fenômeno predominantemente urbano, ou seja, sua distribuição geográfica é muito menos equilibrada do que, por exemplo, a da Igreja evangélica adventista, cujos membros urbanos se destacam dos membros nas áreas rurais na proporção de 1:5,72.

Mais do que isso: o censo de 2000 confirmou que o Budismo sofre um desnível entre o número de fiéis no Estado de São Paulo e o de diversos outros Estados ainda mais drástico do que as duas minorias cristãs acima citadas. Em 1991, foram contados 164.585 budistas explícitos e 143.834 adventistas no Es- 
tado de São Paulo e não surpreende que esses números representaram tanto para o Budismo quanto para a Igreja evangélica adventista as maiores concentrações de fiéis em todo o país. O outro extremo foi o Estado do Acre, onde 1.632 habitantes se identificaram como adventistas, mas nenhuma pessoa como budista. Para os adventistas, o Acre foi o único Estado onde o número de aderentes ficou abaixo de dois mil, enquanto em oito Estados, entre eles Pernambuco e Goiás, o número de budistas não chegou a mil, uma situação acanhada ainda ultrapassada pelo Amapá (145), Tocantins (20), Piauí (127), Paraíba (217), Alagoas (153) e Sergipe (68). Por outro lado, com relação à Igreja evangélica adventista foram registrados dezesseis Estados com um número de fiéis com cinco dígitos, no caso do Budismo, apenas o Rio de Janeiro (22.288) e o Paraná (17.303) chegaram a esse patamar. A mesma tendência encontra-se a respeito da distribuição das instituições budistas existentes no Brasil inteiro. Com base em uma contagem de Rafael Shoji ${ }^{32}$, em setembro de 2003, haviam 156 grupos estabelecidos no Estado de São Paulo, 35 no Rio de Janeiro e 32 no Paraná. Além das 223 instituições nos pontos de concentração de imigrantes asiáticos, foram registrados apenas 86 outros templos e centros budistas no restante do território brasileiro.

Tudo isso aponta para o fato de que o Budismo, além de ser uma religião predominantemente urbana, é apenas relativamente "forte" nos Estados antigamente preferidos pelos imigrantes asiáticos na busca de um lugar de estabelecimento permanente. Fora desses "núcleos", a sua situação numérica é muito precária ou, até mesmo, tão limitada que se pode dizer que, na maior parte do vasto território brasileiro, o Budismo é praticamente inexistente.

\section{Reflexões sobre a situação do Budismo étnico}

Sem considerar os trabalhadores chineses temporariamente contratados na primeira parte do século XIX, os quais pelo menos alguns devem ter praticado o Budismo enquanto estavam no Brasil, o "Budismo étnico" remonta à chegada de centenas de japoneses no navio Kasato-maro que aportou em Santos em 18 de junho de 1908. Entre os 781 passageiros estava o sacerdote Genju Ibaragui, representante da linha budista Nichiren que fundaria, em 1936, perto da cidade de Lins, no Estado de São Paulo, um "núcleo de culto" para seguidores da sua religião. Um ano mais tarde, era consagrado como o único templo budista em solo brasileiro. A instituição permaneceu por quinze anos como uma raridade, uma vez que a primeira geração de imigrantes japoneses tinha vindo para o país com a intenção de ficar apenas por um determinado tempo, o que fez com que a abertura de uma própria instituição budista não fosse levada em consideração. Nos anos de 1950, porém, a partir de uma mudança de mentalidade, sobretudo em relação à derrota do Japão na Segunda Guerra Mundial, a situação mudou: simultaneamente, houve a migração dos imigrantes da área rural para algumas cidades e com eles todas as correntes budistas então presentes estabeleceram-se definitivamente no Brasil com o apoio das suas matrizes no Japão. 
Na primeira metade dos anos de 1960, o campo budista começou a se diferenciar em dois sentidos. Por um lado, em 1962, a colônia chinesa, numericamente a segunda maior comunidade asiática no Brasil depois dos japoneses, inaugurou o templo Mo Ti na cidade de São Paulo. Somente depois de cerca de três décadas, outros templos chineses, bem como a única entidade do budismo coreano, portanto um templo da corrente "étnica" quantitativamente menos forte do Budismo no Brasil, abriram suas portas para os imigrantes e seus descendentes. Por outro lado, o Templo Busshinji no bairro paulista da Liberdade tornou-se o primeiro ponto de referência para os intelectuais da época que, como em outros países ocidentais, sentiam-se atraídos pela prática da meditação bem antes que os integrantes da chamada "contra-cultura" desenvolvessem seu interesse por religiões orientais.

Já no fim dos anos de 1950, portanto ainda antes da mencionada diferenciação do campo budista brasileiro, o Budismo japonês começou a sentir as conseqüências das concessões que o ambiente anfitrião, predominantemente católico, exigia dos imigrantes asiáticos no decorrer do processo da sua aculturação. Além de uma tendência estatisticamente óbvia da desistência de determinadas expressões formais vinculadas à prática doméstica da sua religião tradicional ${ }^{33}$, um número cada vez mais alto de membros de famílias de imigrantes abandonou o Budismo e converteu-se ao Cristianismo. Em 1941, uma minoria de 1,5 declarou-se cristã ${ }^{34}$. Apenas dezessete anos mais tarde a situação tinha mudado dramaticamente: em ambientes urbanos, $50,3 \%$ dos japoneses estabelecidos no Brasil tinham-se convertido ao Cristianismo, em áreas rurais a porcentagem era de 36,5\%. O declínio numérico do Budismo japonês mostrava-se ainda mais claramente através de uma comparação entre as gerações: Dos imigrantes nascidos no Japão, 70,6\% identificaram-se como budistas. Daqueles já nascidos no Brasil, os que se diziam budistas eram 29,9\% (os de segunda geração) ou 19\% (os de terceira geração), respectivamente ${ }^{35}$.

Há indícios claros que a dificuldade de preservar a herança religiosa autóctone dentro das famílias permanece e que esse problema atinge todas as correntes do Budismo étnico presentes no Brasil contemporâneo. Um parâmetro inequívoco nesse sentido é o declínio de budistas de origem asiática no período entre os dois últimos censos nacionais. Baseado em correlações entre as categorias "religião" e "raça", o IBGE contou, em 1991, a presença de 89.971 budistas “amarelos" no país. Em 2000, porém, o número tinha caído para 81.345.

Esse movimento negativo não apenas se reflete nas estatísticas, mas corresponde às observações de religiosos responsáveis pelos templos tradicionais budistas. Como mostra a seguinte citação de uma palestra do Reverendo Ricardo Mário Gonçalves (Shaku Riman), integrante da cúpula do ramo Higashi Honhanji do Budismo Shin (Terra Pura) sobre o futuro do Budismo japonês tradicional no Brasil em maio de 2004:

Na prática, é fácil perceber que os descendentes de japoneses pouco se interes- 
sam pelos templos budistas: estão mais preocupados em se integrarem na sociedade brasileira do que em manterem as tradições de seus ancestrais. Assim, não será um exagero dizer que quando o último imigrante falecer, só resta aos missionários budistas fecharem os templos e regressarem ao Japão, sendo interessante recomendar ainda ao último a partir que desligue a luz antes de seguir para o aeroporto ${ }^{36}$.

Por duas razões, a freqüência ainda relativamente alta dos templos em determinadas ocasiões, não é um motivo para se repensar essa avaliação pessimista: primeiro, especificamente sob as condições da cultura anfitriã, os imigrantes e seus descendentes consideram seus templos não apenas como lugares religiosos, mas também como núcleos de atividades sociais. Por isso, além da função espiritual, esses templos mostram características de centros culturais com programas variados, incluindo karaokê para adolescentes e grupos de dança folclórica para idosos. Segundo, mesmo que os visitantes vão para o templo por motivos religiosos, eles não são necessariamente imediatamente relacionados ao Budismo, mas podem ser expressões do costume relacionado aos cultos de ancestrais, ou seja, a práticas que, no decorrer da história religiosa do Japão, se fundiram com o Budismo. Os representantes dos templos sabem disso, como prova uma outra citação do Reverendo Shaku Riman:

Qualquer pessoa que visite um templo do Budismo Shin ou de outra escola budista tradicional nos fins de semana, fica impressionada com o grande número de pessoas circulando pelo local. Os estacionamentos ficam lotados. São as famílias japonesas que procuram os templos para a celebração dos hôji ou cultos em memória dos familiares falecidos. Sugiro que os visitantes dêem uma olhada nos carros nos estacionamentos. Verão que a maior parte dos mesmos ostenta adesivos ou amuletos das mais diversas "seitas" ou "novas religiões”. Ou seja, as famílias só vão aos templos para os serviços fúnebres, que, tradicionalmente, entre os japoneses, são da alçada dos templos budistas. $\mathrm{Na}$ realidade, elas vivem segundo os ensinamentos das seitas ou novas religiões e desconhecem totalmente os ensinamentos budistas. Excetuando-se um pequeno núcleo de devotos fiéis, geralmente de avançada idade, os japoneses só vão aos templos para os serviços fúnebres ${ }^{37}$.

Essa falta do compromisso com o Budismo não é um fenômeno geograficamente limitado, mas um problema geral que representa um desafio sério para as cúpulas das instituições tradicionais japonesas. Isso se confirma através do seguinte depoimento do Reverendo Wagner Bronzeri (Shaku Haku-Shin), dirigente do templo paranaense Apucarana Nambei Honganji:

Os antigos budistas de imigração estão morrendo e os descendentes, por uma série de questões culturais, ainda mantêm os cultos no templo, mas basta perguntar a qualquer um em meio a essas centenas de participantes que afluem ao templo nos finais de semana se eles são budistas, para cairmos prostrados... menos de $1 \%$ talvez (este número não é oficial... talvez seja menor) se denomina budista, mesmo que nem saiba exatamente o que é a essência da doutrina budista ${ }^{38}$. 
A tendência negativa do desenvolvimento estatístico do "Budismo de imigração" nos últimos anos não apenas resulta da falha de transmissão religiosa dentro das famílias de descendência asiática, mas também da incapacidade das instituições budistas de atrair um novo público fora do próprio ambiente étnico. Isso é uma conseqüência de longo prazo da falta de uma estratégia sistemática na divulgação, cuja expressão direta é o número pequeno de descendentes japoneses lingüística e culturalmente completamente aculturados que se formaram como ministros das suas linhas budistas de acordo com suas tradições familiares, não apenas para satisfazer as necessidades religiosas dentro da própria comunidade, mas também para desempenhar o papel de um "tradutor" entre a sua tradição religiosa e as predisposições espirituais predominantes em um público maior. Recentemente, vários templos começaram a reagir a essa problemática de duas maneiras inter-relacionadas. Primeiro, reconhecendo a manutenção do japonês como o idioma predominante nas atividades dos templos como um dos maiores obstáculos do enraizamento do Budismo na cultura brasileira, foram intensificados os esforços de substituir a língua materna dos imigrantes pelo português. Conforme Gonçalves, na sua função como representante do templo Higashi Honganji no Bairro da Saúde em São Paulo:

O desconhecimento do português por parte dos missionários japoneses fez com que até agora as atividades dos templos tenham sido realizadas quase que exclusivamente em japonês. Hoje, em nossa comunidade, já fazemos pregações em português como complemento aos rituais familiares e também ministramos cursos de iniciação ao Budismo no idioma pátrio. Além disso, nossa comunidade mantém o Instituto Budista de Estudos Missionários, que tem como um de seus objetivos publicar traduções de textos sagrados e livros de divulgação do Budismo Shin em português. Vários livros já foram lançados com sucesso e outros tantos se encontram em fase de preparação ${ }^{39}$.

Simultaneamente, têm sido oferecidos cursos introdutórios ao Budismo abertos para o público geral também em português. Trata-se de séries de encontros sobre diversos temas cuja elaboração deve facilitar a identificação do Budismo como uma religião que se direciona a todos os seres humanos, independente de características específicas como, por exemplo, sua nacionalidade. Todavia, do ponto de vista de alguém não-engajado nessas atividades, a avaliação da sua primeira fase não parece muito auspiciosa. Segundo os organizadores dos seminários realizados no Templo Higashi Honganji em São Paulo, por exemplo, as aulas dadas em 2003 resultaram em "uma bela safra de neófitos". Em termos quantitativos, porém, o resultado foi menos prometedor do que a metáfora fez acreditar: a frase eufórica referiu-se a apenas catorze pessoas que tinham pedido a iniciação ao Budismo Terra Pura!

Como os outros dados resumidos nesse parágrafo, o último caso citado intensifica as dúvidas sobre a adequação da imagem pública de um "Budismo crescente" repetidamente divulgada pela mídia. Ao mesmo tempo, percebe-se 
uma discrepância entre a leitura da expressão "bela safra" do ponto de vista empírico e uma retórica religiosa através da qual uma insignificância numérica de budistas recém-iniciados transforma-se em um "bom resultado" de esforços proselitistas de acordo com o lema: “a prosperidade de uma Escola não depende de reunir muitas pessoas, mas sim em formar um único autêntico praticante" ${ }^{40}$.

\section{Problemas inerentes ao universo dos "budistas de conversão"}

Conforme o IBGE, 146.437 brasileiros “brancos”, “pardos”, “pretos” e “indígenas” declararam-se budistas em 1991. Em 2000, o número havia caído para 133.528. Devido a essa diferença de 12.909 pessoas, há boas razões para crer que a tendência negativa do desenvolvimento estatístico do Budismo brasileiro não apenas atingiu o "Budismo étnico", mas também o "Budismo de conversão". Porém, a situação da maioria dos brasileiros não-vinculados ao ambiente étnico, que em 2000 não voltaram a se identificar como adeptos do Budismo, é mais complexa do que a sua categorização como (ex)-“budistas de conversão” parece sugerir, uma vez que a adesão de um indivíduo ao Budismo é tipicamente um processo gradual de aproximação motivado pela busca de uma oferta espiritual promissora. Enquanto a identificação com o Budismo tem sido tradicionalmente vinculada ao ato simbólico da repetição da fórmula tripla "eu tomo meu refúgio ao Buda, a sua doutrina e sua comunidade", diversos grupos budistas ocidentais contemporâneos não possuem um critério fixo que ajudaria o indivíduo a saber se ele já é budista propriamente dito ou ainda somente um "candidato". Em outras palavras: diferentemente de budistas por nascimento, cuja identificação com a sua tradição espiritual é fruto "natural" da uma socialização primária familiar, muitas vezes, um ocidental que se abriu para o Budismo apenas como adolescente ou adulto reconstrói sua identidade religiosa "por conta própria".

A insegurança de um novo adepto sobre o próprio status deve ser menor em comunidades budistas como a New Kadampa Tradition que se assemelham em suas estruturas internas e estratégias externas ao tipo institucional de um cult movement, ou seja, que exigem dos seus membros um alto grau de compromisso e uma adesão exclusiva a partir de uma identificação profunda com os padrões, valores e idéias do grupo. Todavia, quanto menos o interesse pelo Budismo for contextualizado por uma "estrutura de plausibilidade" budista, maior é a probabilidade de que a paixão pelo Budismo seja apenas passageira e não leve a uma autoimagem suficientemente estável para se declarar "budista" repetidamente nos censos nacionais consecutivos.

Isso não vale necessariamente para os "andarilhos" dentro do vasto espectro do Budismo, que se associam a grupos de linhas diferentes no decorrer dos seus percursos religiosos, mas sim, por exemplo, para praticantes de determinados métodos do Budismo que dizem de si mesmos: "me sentia muito insegura de dizer que era budista, eu não sabia se era, efetivamente", ou: "sei que os ensinamentos funcionam", porém, “até hoje não sei se sou budista”41. 
Mais claramente articulam-se as dúvidas sobre a própria identidade religiosa quando alguém atraído pelo Budismo sente os "ecos" da sua educação familiar anterior, como exemplificam os dois seguintes depoimentos:

Quando fui visitar a sala de meditação, achei tudo muito esquisito, estranho. Onde estavam meu Jesusinho, minha Nossa Senhora, meus santinhos? Como é que eu estava num lugar que não tinha nenhum Cristo? Minha mãe tão católica, eu desde criança $[. .$.$] me sentia extremamente culpada, mas alguma$ coisa me fazia bem ${ }^{42}$.

Eu ainda sou apenas um simpatizante do Budismo e não um convertido (detesto essa palavra, mas me faltou outra). Nosso país é um país tradicionalmente católico e a maioria da população, assim como eu, foi criada e educada nos moldes da igreja católica, que traz a figura de Deus personificado, à nossa imagem e semelhança. Talvez seja esse o ponto crucial, o conceito mais difícil de ser mudado ou entendido, visto que no Budismo não existe a figura do Deus personificado ${ }^{43}$.

Não se sabe quantos "budistas inseguros" ou "semi-convertidos", que diante da exigência do IBGE de se declarar inequivocamente a favor de uma preferência religiosa, suspenderam suas dúvidas e optaram por uma cruz na categoria "Budismo". Se tivesse sido realmente uma quantia considerável, a situação do Budismo brasileiro não-vinculado a um ambiente étnico seria ainda mais precária do que os números indicam.

\section{Anotações sobre o status político precário do Budismo brasileiro}

Apesar de o Budismo brasileiro estar quantitativamente em uma posição acanhada, a sua força pública seria maior se todas as suas correntes cooperassem entre si em função de objetivos comuns. Quando se lembra que a única organização "ecumênica” do Budismo brasileiro é a Federação das Seitas Budistas no Brasil, fundada em 1958 para reunir apenas as principais escolas japonesas numa organização coletiva, evidencia-se a precariedade da sua situação política no país. Para reconhecer a dimensão restrita dessa institucionalização em favor de apenas uma parte do campo budista brasileiro, deve-se lembrar que, desde 1955, a maioria de cerca de 220 mil budistas registrados na Alemanha é oficialmente representada pela União Budista Alemã e que, graças a esforços coletivos, o ensino religioso budista foi recentemente implantado nos currículos das escolas públicas na cidade de Berlim. Na Áustria, onde também uma corporação nacional engaja-se pelos interesses dos seus associados, o ensino religioso budista existe desde o segundo semestre de 1993 em todas as províncias. Essas conquistas indicam que a disposição dos representantes das diversas linhas budistas para superar suas divergências doutrinárias e para agir juntos faz com que o Budismo, mesmo que sendo em ambos os países uma minoria em termos estatísticos, seja considerado uma religião respeitada, cujas articulações são dignas de serem ouvidas nas discussões públicas de ambos os países europeus. 
Em vários sentidos, o Budismo brasileiro está longe de chegar à mesma harmonia entre suas correntes. Por razões formais, este artigo oferece apenas espaço para esboçar dois aspectos. Primeiro, há relatórios sobre as dificuldades de vencer as tensões causadas pela oposição de oficiais tradicionais de templos predominantemente étnicos contra os planos "modernistas" de abrir a instituição para um público não-descendente de asiáticos. Um exemplo evidente para esse tipo de conflito é o templo Busshinji no bairro da Liberdade em São Paulo, que se destaca por três casos problemáticos em sua história recente. O alvo da primeira polêmica foi Tokuda Ryotan, que logo depois da sua chegada em 1968, foi criticado pela cúpula da instituição, que se mostrou incomodada por seu estilo não-convencional. Um destino semelhante sofreu Daigyo Moriyama Roshi, que assumiu a liderança espiritual do Busshinji em 1993 depois de ter divulgado, desde os anos de 1960, o Zen Budismo para o público norte-americano da Califórnia. Dois anos mais tarde, as fricções crescentes entre ele e a hierarquia local levaram a sede japonesa a interferir substituindo Moriyama pela Monja Coen. Por um lado, respeitada como qualificada professora de dharma pelos praticantes ocidentais, por outro lado, tolerada na sua dupla função pela cúpula tradicional do templo, a Monja Coen se manteve na chefia da instituição até o fim do ano 2000, ou seja, até o momento em que o Reverendo Koichi Miyoshi, mandado para o Brasil pela sede japonesa do Soto Zen, tomou posse como novo líder espiritual do Busshinji. A conseqüência desse fato foi que a monja rompeu com a hierarquia do Busshinji no início de 2001. Todos os casos citados apontam para uma determinada incompatibilidade não resolvida entre o Budismo "étnico" e um Budismo ocidentalizado ${ }^{44}$, portanto, revela uma oposição latente dentro do campo budista brasileiro em geral, que contribui para um enfraquecimento do Budismo como fenômeno macro-político.

A segunda linha principal de conflito que divide o campo dos grupos de origem japonesa em duas grandes "frentes" consta com a animosidade, para não dizer hostilidade, entre o Budismo Terra Pura e a Soka Gakkai. Conforme várias afirmações periodicamente repetidas, os porta-vozes do Budismo Terra Pura negam o caráter budista da Soka Gakkai por apenas apresentar uma das múltiplas "novas religiões japonesas" cujo sucesso duvidoso deve-se a "uma estrutura organizacional tipo empresa", "técnicas agressivas de persuasão" e "um discurso milagreiro" 45 . Do ponto de vista da História da Religião, porém, o grupo em questão não é apenas um dos maiores movimentos leigos budistas do mundo, mas com seus cerca de 120 mil adeptos brasileiros é também o "ramo de conversão" numericamente mais forte no país, cuja exclusão do conjunto dos grupos budistas legítimos não apenas reduz o verdadeiro peso estatístico do Budismo brasileiro pela metade, mas também prejudica a imagem pública de uma religião geralmente considerada tolerante e pacifista. 


\section{Considerações finais: a pesquisa sobre o Budismo brasileiro como tarefa contínua}

Apesar da sua relativa insignificância estatística do ponto de vista de números absolutos, a pesquisa sobre o Budismo brasileiro permanecerá um desafio contínuo para a Ciência da Religião que, pelo seu perfil acadêmico, tem um interesse imediato por religiões não-cristãs, inclusive as orientais e sua adoção no Ocidente. Não se deve esquecer que o número de seguidores do Budismo é maior do que o dos adeptos do Candomblé, uma religião inquestionavelmente considerada relevante para a pesquisa nacional. O mesmo vale para o Judaísmo, o Islã e o Hinduísmo, cuja presença coletiva no Brasil é numericamente menos acentuada do que a do Budismo ${ }^{46}$.

Mas, independentemente da dimensão estatística, há motivos substanciais para não deixar de se acompanhar o futuro desenvolvimento do Budismo brasileiro. Para mencionar apenas dois, vale lembrar primeiro que uma grande parte das pesquisas sobre o Budismo ocidental foi feita em países protestantes, o que já provocou a pergunta de que maneira o processo de adoção dessa religião assume um caráter diferente em um contexto cultural predominantemente católico. Os cientistas da religião brasileiros interessados por essa dinâmica, como, por exemplo, Rafael Shoji ${ }^{47}$ e Cristina Rocha ${ }^{48}$, poderão desempenhar um papel importante na análise do Budismo contemporâneo em termos mundiais e contribuir para a futura discussão acadêmica internacional sobre esse assunto.

Uma segunda razão para não deixar de investir energia na pesquisa do Budismo brasileiro tem a ver com o subcampo do Budismo tibetano, um fenômeno pouco mencionado nos parágrafos anteriores. Embora algumas das suas características particularmente acentuadas no Brasil apontem para tendências mais gerais no decorrer do processo da transformação do Vajrayna de um ramo culturalmente muito especializado para uma religião mundial como conseqüência da ocupação chinesa da sua pátria e sua posterior dispersão global. Particularmente grupos como o do Chagdud Tulku ${ }^{49}$, falecido em 2002, o primeiro líder espiritual tibetano que se estabeleceu no país, e fenômenos representados pelos budistas brasileiros Lama Segyu e Lama Michel, ambos considerados por seus seguidores reencarnações de grandes mestres tibetanos, deveriam receber mais atenção dos pesquisadores de um ponto de vista puramente acadêmico, independentemente do ibope que o Budismo brasileiro desfruta na mídia nacional.

Notas

l Cf. a capa da revista Terra, ago. 2003.

2 Cf. a manchete na capa da revista Isto É, $1^{\text {o }}$ out. 2003.

3 Cf. "Ato multirreligioso celebra 80 anos da Folha", Folha de S. Paulo, 18 fev. 2001.

4 Cf. “Um Budismo de resultados”, Isto É, 9 maio 2001. 
5 Cf. “O Boni me sacaneou”, Isto É, 8 jan. 2001.

6 Cf. “O Brasil dos Budas”, Isto É, 12 mar. 1997, pp. 62-70.

7 Cf. "Meditação a ginástica do espírito", Galileu, n. 88, 2000.

8 Por exemplo, a cineasta Ana Carolina, cf. "Ana Carolina e a comédia das diferenças", Estado de S. Paulo, 9 jul. 2000.

9 Cf. Colin Campbell, "A orientalização do Ocidente: reflexões sobre uma nova teodicéia para um novo milênio", Religião e Sociedade, vol. 18, n. 1, 1997, pp. 522.

10 Rodney Stark e Roger Finke, Acts of Faith. Explaining the Human Side of Religion, Berkeley/London, Los Angeles/ University of California Press, 2000, p.18 f.

11 Cf. "Templos revestem budistas de novas visões de mundo", Estado de S. Paulo, 27 out. 1998.

12 Cf. "Monja ensina meditação nos parques", Folha de S. Paulo, 28 jun. 2001, Caderno Equilíbrio, p. 7.

13 Cf. "Meditação em movimento", Correio Braziliense, 21 ago. 2001, on line: <http:/ /www2.correioweb.com.br/cw/2001-08-21/mat_50577.htm>, consultado em 15 jul. 2004.

14 A marcha para Jesus realizada em 26 de junho de 2004, por exemplo, contou com, nas pior das hipóteses, 350 mil participantes. Cf. "Marcha reúne evangélicos na zona norte", Folha de S. Paulo, 27 jun. 2004, Caderno Cotidiano.

15 Citação da capa da revista Época, no 265,16 jun. 2003.

16 Cf. "Budistas erguem templo de RS 12\$ mi”, Folha de S. Paulo, 21 set. 2003, Caderno Cotidiano.

17 Cf. "Inauguração de templo budista atrai cerca de 2.000 pessoas", Folha Online, 6 out. 2003.

18 “Templo budista é aberto em Cotia”, Folha de S. Paulo, 6 out. 2003, Caderno Cotidiano.

19 "Governo Lula autoriza 3,4 cursos por dia", Folha de S. Paulo, 12 jun. 2004, Caderno Cotidiano.

20 "Universal lota templo para 10 mil em SP", Folha de S. Paulo, 2 fev. 1998, Caderno Brasil.

21 "Evangélicos constroem uma nova sede em Minas, a maior no Estado", Folha de $S$. Paulo, 4 jan. 2004, Caderno Brasil.

22 Cf. Jan Nattier, "Who is a Buddhist? Charting the Landscape of Buddhist America", em Charles S. Prebish e Kenneth K. Tanaka (eds.), The Faces of Buddhism in America, Berkeley, University of California Press, 1998, pp. 183-195.

23 Robert T. Carpenter, "Wade Clark Roof: The Transplantation of Seicho-no-ie from Japan to Brazil: Moving Beyond the Ethnic Enclave", Journal of Contemporary Religion, vol. 10, n. 1, 1995, pp. 41-54, especialmente p. 48.

24 Cf. o segundo capítulo em Rodney Stark e William S. Bainbridge, The Future of Religion: Secularization, Revival, and Cult Formation, Berkeley, University of 
California Press, 1985. Uma aplicação da tipologia desenvolvida por Stark e Baindbridge ao campo do Budismo ocidental encontra-se em Jan Nattier, op. cit.

25 Cf. Ronan Alves Pereira, O Budismo leigo da Sôka Gakkai no Brasil: da revolução humana à utopia mundial, Tese de Doutorado, Campinas, IFCH-Unicamp, 2001.

26 Cf. Rafael Shoji, "Estratégias de adaptação do Budismo chinês: brasileiros e chineses na Fo Kuang Shan", em Frank Usarski (org.), O Budismo no Brasil, São Paulo, Lorosae, 2002, pp. 125-149, especialmente, p. 147.

27 Cf. Frank Usarski, "Seu caloroso coração brasileiro e a energia pura de Maitreya atuam muito bem juntos - Reflexões sobre Lama Michel”, em Frank Usarski (org.), op. cit., pp. 287-317.

28 Gabriela Bastos Soares, O biopoder na contemporaneidade: o espirito do corpo e a alternativa budista, Tese de Doutorado, Rio de Janeiro, UERJ, 2004, p. 139.

29 Idem, p. 144.

30 Cf. Cândido Procópio Ferreira de Camargo, Católicos, protestantes, espiritas, Petrópolis, Vozes, 1973, pp. 48 e ss.

31 Cf. Paul David Numrich, Old Wisdom in the New World: Americanization in Two Immigrant Theravada Buddhist Temples, Knoxville, University of Tenessee Press, 1996.

32 Cf. Rafael Shoji, The Nativization of East Asian Buddhism in Brazil, Tese de Doutorado em Ciência da Religião, Universidade de Hannover, 2004.

33 Cf. Yukio Fuji e T. Lynn Smith, The Aculturation of the Japanese Immigrants in Brazil, Gainesville, University of Florida Press, 1959, pp. 43 e ss.

34 Cf. Idem, p. 14.

35 Cf. Takashi Maeyama, "Religião, parentesco e as classes médias dos japoneses no Brasil urbano", em Hiroshi Saito e Takashi Maeyama, Assimilação e integração dos japoneses no Brasil, Petrópolis, Vozes, pp. 240-272, especialmente p. 248.

36 Ricardo Mário Gonçalves, O futuro dos templos budistas no Brasil (Conferência Pública realizada em Araçatuba em 23/5/2004, durante as celebrações do Cinqüentenário do Templo Araçatuba Nambei Honganji), divulgado via lista de discussão Budismo_Shin@yahoo.com.br.

37 Afirmação feita no fórum eletrônico Budismo_Shin@yahoo.com.br via mensagem enviada no dia 12 de dezembro de 2003.

38 Afirmação feita no fórum eletrônico buddhismo@topica.com via mensagem enviada no dia 23 de setembro de 2004 .

39 Ricardo Mário Gonçalves, op. cit.

40 Essa citação de Reverendo Ricardo Mário Gonçalves encontra-se também no e-mail citado.

41 Vera de Andrade de Silva, Conversão ao Budismo Tibetano. Trajetórias em três grupos de São Paulo, Dissertação de Mestrado, São Paulo, PUC-SP, 2002, pp. 156 e 132 respectivamente.

42 Idem, p. 156. 
43 Citação de um e-mail enviado para mim por Luiz Fernando via lista buddhismo@topica.com em 23 de setembro de 2004.

44 Cf. Cristina Rocha, "Zazen or Not Zazen? The Predicament of Sōtōhū's Kaikyōshi”, em Japanese Journal of Religious Studies 31/1 (2004), pp. 163-184, especialmente pp. 173 e ss.

45 Citações de um e-mail enviado para mim pelo Reverendo Ricardo Mário Gonçalves (Shaku Riman) via lista eletrônica Budismo_Shin@yahoogrupos.com em 9 de dezembro de 2003.

46 Cf. Shoji, op. cit., p. 23.

47 Cf. Idem.

48 Cf. Cristina Moreira da Rocha, Zen in Brazil: The Quest for Cosmopolitan Modernity, Ph.D. Thesis, Center for Cultural Research, University of Western Sidney, 2003.

49 Cf. Daniel Alves, Seres de Sonho: percursos religioso e práticas espirituais num centro budista ao Sul do Brasil, Dissertação de mestrado em Antropologia Social, Porto Alegre, Universidade Federal do Rio Grande do Sul, 2004.

RESUMO - EMBORA a mídia venha freqüentemente afirmando que o Budismo é uma das religiões mais crescentes no Brasil, as pesquisas, inclusive os dois últimos censos nacionais, revelam o contrário. $\mathrm{O}$ artigo confronta a imagem pública exagerada com a realidade empírica e discute de maneira sistemática os problemas e desafios principais com os quais o Budismo brasileiro contemporâneo é confrontado.

ABSTRACT - CONTRARY to the positive image maintaned by the mass media there is no evidence for the claim that Buddhism is one of the most dramaticaly growing religions in Brazil. From the empirical point of view, rather the opposite is true. The article confronts the public image with the results of academic research including the last two national census, and dicusses the main problems and challenges the contemporary Brazilian Buddhism is confronted with.

Frank Usarski é doutor em Ciência da Religião pela Universidade de Hannover e professor do Programa de Pós-Graduação em Ciências da Religião e do Departamento de Teologia e Ciências da Religião da PUC, São Paulo, em cujo nome organiza o full text jornal eletrônico Rever - Revista de Estudos da Religião, www.pucsp.br/rever .

Texto recebido e aceito para publicação em 29 de setembro de 2004. 